\title{
Análise físico-química do óleo-resina e variabilidade genética de copaíba na Floresta Nacional do Tapajós
}

\author{
Ederly Santos Silva(1), Caroline de Souza Mathias ${ }^{(2)}$, Milena Campelo Freitas de Lima(2), \\ Valdir Florêncio da Veiga Junior ${ }^{(2)}$, Doriane Picanço Rodrigues ${ }^{(1)}$ e Charles Roland Clement ${ }^{(3)}$
}

(1)Universidade Federal do Amazonas (Ufam), Laboratório de Evolução Aplicada, Instituto de Ciências Biológicas, Avenida General Rodrigo Octávio Jordão Ramos, no6.200, Coroado, CEP 69080-900 Manaus, AM. E-mail: ederly.silva@bol.com.br, prdoriane@gmail.com (2)Ufam, Departamento de Química, Instituto de Ciências Exatas. E-mail: mathias.caroline@gmail.com, mile_campelo@yahoo.com.br, valdirveiga@ufam.edu.br ${ }^{(3)}$ Instituto Nacional de Pesquisas da Amazônia, Coordenação de Tecnologia e Inovação, Avenida André Araújo, no 2,936, Aleixo, CEP 69060-001 Manaus, AM. E-mail: cclement@inpa.gov.br

Resumo - O objetivo deste trabalho foi caracterizar o óleo-resina da copaíba (Copaifera reticulata) e estimar, por meio de marcadores microssatélites, a variabilidade genética da espécie na Floresta Nacional do Tapajós, PA. A amostragem foi realizada em duas áreas, distanciadas de $5 \mathrm{~km}$, em 136 árvores. A diversidade genética foi avaliada com seis marcadores microssatélites derivados de $C$. langsdorffii, e o óleo obtido de 30 árvores (15 de cada área) foi caracterizado em termos físicos e químicos. O óleo C. reticulata apresenta aspecto líquido, fino, odor fraco e de coloração amarelo-dourada (73,3\% das plantas), com viscosidade muito variável (18 a $187 \mathrm{~Pa}-\mathrm{s})$ e densidade média de $0,975 \pm 0,049 \mathrm{~g} \mathrm{~cm}^{-3}$. O índice de acidez variou de 9,62 a 10,17 $\mathrm{mg} \mathrm{g}^{-1} \mathrm{de} \mathrm{KOH}$ e o de saponificação de 100,63 a 109,84 $\mathrm{mg} \mathrm{g}^{-1}$. A análise molecular identificou 78 alelos, com média de 13 por loco. A heterozigosidade esperada variou 0,59 a 0,85 (média de 0,75 ), com nível de endogamia de 0,375 a 0,419 . Houve pouca diferenciação genética entre as populações das diferentes áreas de coleta $\left(F_{S T}=0,030\right)$, mas a variabilidade foi maior entre os grupos genéticos detectados pelo programa Structure $\left(\mathrm{F}_{\mathrm{ST}}=0,070\right)$. Essa maior variabilidade indica que não há ameaças à conservação genética da copaíba, em médio prazo.

Termos para indexação: Copaifera reticulata, conservação in situ, endogamia, estrutura genética, manejo extrativista, variabilidade físico-química.

\section{Physico-chemical analysis of the oleoresin and genetic variability of copaiba in the Tapajós National Forest, Brazil}

\begin{abstract}
The objective of this work was to characterize the oleoresin of copaiba (Copaifera reticulata) and to estimate genetic variability of the species in the Tapajós National Forest, PA, Brazil, using microsatellite markers. Sampling was performed in two areas, $5 \mathrm{~km}$ apart, in 136 trees. Genetic diversity was evaluated with six microsatellite markers derived from $C$. langsdorffii, and the oleoresin obtained from 30 trees (15 from each area) was physically and chemically characterized. Oleoresin from $C$. reticulate has a liquid, thin aspect, with a weak odor and yellowish-gilded color ( $73.3 \%$ of the plants), highly variable viscosity (18 to $187 \mathrm{~Pa}-\mathrm{s}$ ), and mean density of $0,975 \pm 0,049 \mathrm{~g} \mathrm{~cm}^{-3}$. Its acidity index varied from 9.62 to $10.17 \mathrm{mg} \mathrm{g}^{-1}$ of $\mathrm{KOH}$ and the saponification index from 100.63 to $109.84 \mathrm{mg} \mathrm{g}^{-1}$. The molecular analysis identified 78 alleles, with an average of 13 per locus. The expected heterozygosity varied from 0.59 to 0.85 (mean of 0.75 ) and the inbreeding level, from 0.375 to 0.419 . The genetic differentiation between populations in the different sampling areas was low $\left(\mathrm{F}_{\mathrm{ST}}=0.030\right)$, but the variability was higher between the genetic groups detected by Structure software $\left(\mathrm{F}_{\mathrm{ST}}=0.070\right)$. This higher variability indicates that the genetic diversity of copaiba is not threatened in the mid-term.
\end{abstract}

Index terms: Copaifera reticulata, in situ conservation, inbreeding, genetic structure, extractive management, physicochemical variability.

\section{Introdução}

A extração de óleo-resina de diversas espécies de copaíba é uma prática comum nas comunidades do interior da Amazônia. No entanto, a disponibilidade deste produto é limitada, principalmente quanto aos aspectos de qualidade, regularidade de oferta e quantidade (Homma, 1993). Para que as plantas sujeitas à extração não tenham sua sobrevivência ameaçada, estratégias adequadas de manejo devem ser utilizadas. Para isso, é importante que se entenda e quantifique a variabilidade genética existente entre e dentro das populações. A análise físico-química do óleo-resina 
de copaíba também é importante para elaboração de um plano de manejo extrativista, pois permite padronizar o óleo-resina quanto à sua coloração, viscosidade e densidade.

Entre os produtos florestais não madeireiros (PFNM), destaca-se a Copaifera reticulata Ducke (Fabaceae), conhecida vulgarmente como copaíba ou copaibarana. Espécie de ampla distribuição na Floresta Nacional do Tapajós, bem como na Amazônia Central de norte a sul (Martins-da-Silva et al., 2008), a copaíba produz óleo-resina com alta demanda no mercado amazônico de fitofármacos e alguma demanda para o de cosméticos (Veiga Junior \& Pinto, 2002). Sua extração sempre foi realizada de forma tradicional e em pequena escala; no entanto, a procura cresceu tanto, que a extração ganhou escala semicomercial e até comercial em algumas localidades. Na Floresta Nacional do Tapajós, no entanto, sua comercialização estagnou-se recentemente. Na Amazônia, a demanda é atendida por diversas espécies que, muitas vezes, têm seus óleo-resinas misturados antes da comercialização (Veiga Junior \& Pinto, 2002).

Para que este recurso tenha produção garantida nas comunidades, é necessário que ocorram ações de manejo para a melhoria do extrativismo. Nesse sentido, um estudo da variabilidade genética das populações e da química do óleo é importante para elaboração de um plano de manejo que possa competir com outros usos da terra, na Floresta Nacional do Tapajós.

As características químicas do óleo-resina são reconhecidamente variáveis nas diversas espécies de copaíba, e diferentes características são procuradas pelas indústrias farmacêuticas e cosméticas (Veiga Junior \& Pinto, 2002). O óleo-resina é composto de misturas de sesquiterpenos e diterpenos. Os sesquiterpenos são responsáveis pelo aroma e também pela atividade anti-inflamatória do óleo-resina (Barreto Junior et al., 2005). Entre as características físico-químicas, a baixa viscosidade e acidez do óleo-resina de copaíba são importantes para o processamento farmacêutico; em contraste, a elevada viscosidade e acidez são importantes para uso cosmético, como a produção de sabonetes, xampus e condicionadores (Veiga Junior \& Pinto, 2002; Cascon, 2004). Conhecer estas características de antemão permitiria às comunidades comercializar melhor seu produto.

Marcadores microssatélites, ou SSR (sequências simples repetitivas), são amplamente encontrados no genoma de eucariotos, apresentam altas taxas de mutação e são codominantes. Por causa dessas qualidades, estes marcadores têm sido amplamente utilizados em estudos de genética de populações (Kalia et al., 2011).

Oito marcadores microssatélites foram desenvolvidos para Copaifera langsdorffii Desf., a partir de bibliotecas enriquecidas, e testados em 96 indivíduos provenientes de matas da galeria do Distrito Federal (Ciampi et al., 2000). Todos os locos foram altamente multialélicos, o que abriu a perspectiva para o aprofundamento de estudos genéticos em copaíba e espécies afins, pois essa característica representa uma ferramenta poderosa para que se obtenha dados genéticos populacionais necessários à elaboração de um programa de manejo.

O objetivo deste trabalho foi caracterizar o óleo-resina da copaíba ( $C$. reticulata) e estimar, por meio de marcadores microssatélites, a variabilidade genética da espécie na Floresta Nacional do Tapajós, PA.

\section{Material e Métodos}

A pesquisa de campo foi realizada na Floresta Nacional (Flona) do Tapajós, Pará $\left(2^{\circ} 45^{\prime}\right.$ e $4^{\circ} 10^{\prime} \mathrm{S}$ e $54^{\circ} 45^{\prime}$ e $\left.55^{\circ} 30^{\prime} \mathrm{W}\right)$. Esta Flona é uma unidade de conservação de uso sustentável, com cobertura vegetal típica da Floresta Amazônica e diferentes tipos de florestas associadas: tropical densa, tropical aluvial, tropical aberta e floresta secundária. O tipo predominante na área do estudo é a floresta tropical densa. O clima local é do tipo Ami, quente e úmido, conforme classificação de Köppen, com temperatura média anual entre 25 e $26^{\circ} \mathrm{C}$, umidade relativa superior a $80 \%$ durante todo o ano, e aproximadamente $2.000 \mathrm{~mm}$ anuais de precipitação pluvial, com período de estiagem (precipitações menores que $60 \mathrm{~mm}$ ) de quatro meses.

Duzentas árvores adultas de copaíba ( $C$. reticulata) foram identificadas, com a ajuda de quatro extratores das comunidades de Pedreira e São Domingos, no período de fevereiro a junho de 2009, nas áreas adjacentes aos Km 67 e 72 da BR-163 (Santarém-Cuiabá). Esses locais são áreas de coleta objetivadas pelo Instituto Brasileiro do Meio Ambiente e dos Recursos Naturais Renováveis (Ibama), Santarém, PA. Um pedaço de câmbio do tronco de cada árvore foi coletado, acondicionado em saco de papel com sílica enrolado em saco plástico e transportado em caixa de isopor com gelo para o Laboratório de Evolução Aplicada, da Universidade Federal do Amazonas (Ufam), onde os pedaços foram armazenadas em freezer $\left(-20^{\circ} \mathrm{C}\right)$ até a extração do DNA. Das 200 amostras coletadas, foram utilizadas somente 136 (72 amostras do Km 67 e 64 amostras do $\mathrm{Km}$ 72), em razão da oxidação das demais. 
Para caracterização do óleo-resina, 15 amostras de cada uma das áreas foram autorizadas pelo Ibama, e retiradas, com trado, de árvores com diâmetro à altura do peito superior a $40 \mathrm{~cm}$. As amostras foram acondicionadas em garrafas individuais e transportadas ao Laboratório de Química da Ufam, onde foram recondicionadas em garrafas de vidro até a análise.

Para a classificação da coloração dos óleos-resina, utilizou-se a Tabela de cores proposta por Rigamonte-Azevedo et al. (2006), pela qual, por comparação visual, as amostras foram classificadas como incolores, amarelo-claras, amarelo-médias, amarelo-douradas e acastanhadas. A densidade das amostras foi medida em um picnômetro previamente calibrado, com capacidade máxima de $1 \mathrm{~mL}$ à temperatura ambiente $\left(25 \pm 1^{\circ} \mathrm{C}\right)$. Para a determinação da viscosidade, foi utilizado um viscosímetro de Ostwald, acoplado a um banho termostático a $50^{\circ} \mathrm{C}$. As análises de densidade e viscosidade foram realizadas em triplicata para cada amostra, com média e desvio-padrão estimados.

As amostras de óleo-resina foram recondicionadas em vidros âmbar de $60 \mathrm{~mL}$, para análise química no Centro de Biotecnologia da Amazônia, Manaus, AM. O índice de saponificação foi determinado pela quantidade $(\mathrm{mg})$ de $\mathrm{KOH}$ necessária para que um grama de gordura se transforme em sabão (Horwitz, 2005). O índice de refração foi determinado segundo as normas da Horwitz (2005), e o índice de éster, pela quantidade ( $\mathrm{g}$ ) de $\mathrm{KOH}$ necessária para saponificar um grama de óleo neutro (Vasconcelos \& Godinho, 2002).

A extração do DNA genômico foi realizada com o reagente CTAB 2\% (Doyle \& Doyle, 1987) com modificações. Depois de extraído, o DNA genômico foi quantificado, por meio da análise comparativa de cada amostra com o DNA fago de peso molecular conhecido

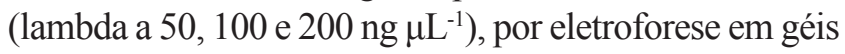
de agarose a $1 \%$, corados com GelRed (Uniscience, São Paulo, SP, Brasil). Posteriormente, o DNA foi diluído em água MilliQ a $10 \mathrm{ng} \mu \mathrm{L}^{-1}$.

Foram testados oito pares de iniciadores derivados da Copaifera langsdorffii (Ciampi et al., 2000). Para a detecção dos produtos por fluorescência, adicionou-se a extremidade do iniciador "Forward" de cada loco à sequência M13 (5'TGTAAAACGACGGCCAGT 3'). As reações em cadeia de polimerase (PCR) tiveram volume final de $10 \mu \mathrm{L}$, com $4 \mu \mathrm{L}$ de DNA genômico, $1 \mu \mathrm{L}$ de tampão $10 \mathrm{X}$ (Tris $\mathrm{HCl} 100 \mu \mathrm{mol} \mathrm{mL} \mathrm{m}^{-1}, \mathrm{KCl}$ $\left.500 \mu \mathrm{mol} \mathrm{mL} \mathrm{m}^{-1}, \mathrm{pH} 8.4\right), 1 \mu \mathrm{L}$ dNTP $\left(2,5 \mathrm{nmol} \mathrm{mL}^{-1}\right), 1 \mu \mathrm{L}$ de $\mathrm{MgCl}_{2}(25 \mu \mathrm{mol} \mathrm{mL}-1), 0,8 \mu \mathrm{L}$ de BSA $\left(2,5 \mathrm{nmol} \mathrm{mL}^{-1}\right)$, $1 \mu \mathrm{L}$ do iniciador Reverse $\left(2,5 \mathrm{nmol} \mathrm{mL}^{-1}\right), 0,5 \mu \mathrm{L}$ do iniciador Forward $\left(1,25 \mathrm{nmol} \mathrm{mL}^{-1}\right), 0,5 \mu \mathrm{L}$ do iniciador M13 (1,25 nmol mL-1) marcado com fluorescência, e $0,2 \mu \mathrm{L}$ de enzima Taq polimerase $\left(5 \mathrm{U}_{\mu} \mathrm{L}^{-1}\right)$ (Biotools B\&M Labs, Madri, Espanha).

As amplificações foram realizadas em termociclador Veriti (Applied Biosystems, Foster City, CA, EUA) conforme o programa: $94^{\circ} \mathrm{C}$ por $2 \mathrm{~min} ; 25$ ciclos de $94^{\circ} \mathrm{C}$ por $10 \mathrm{~s}$ à temperatura de anelamento otimizada para cada loco $-50^{\circ} \mathrm{C}$, para os locos CL01, CL02, CL06, CL20, CL27, CL32 e CL34; $54^{\circ} \mathrm{C}$, no loco CL20; e $56^{\circ} \mathrm{C}$, no loco CL39 - por $20 \mathrm{~s} ; 72^{\circ} \mathrm{C}$ por $30 \mathrm{~s}$; um ciclo de $72^{\circ} \mathrm{C}$ por $10 \mathrm{~min} ; 20$ ciclos de $94^{\circ} \mathrm{C}$ por $10 \mathrm{~s} ; 50^{\circ} \mathrm{C}$ por $20 \mathrm{~s} ; 72^{\circ} \mathrm{C}$ por $30 \mathrm{~s}$; e uma extensão a $72^{\circ} \mathrm{C}$ por $30 \mathrm{~min}$. Os produtos gerados pela PCR de cada loco foram diluídos, e ROX e formamida foram adicionados para a genotipagem em ABI 3130 (Applied Biosystems, Foster City, CA, EUA). A estimativa do tamanho dos alelos foi realizada com o programa GeneMapper v.4.0 (Applied Biosystems, Foster City, CA, EUA).

As frequências alélicas dos locos foram calculadas por meio do programa Convert (Glaubitz, 2004). O programa Structure versão 2.3.2.1 (Hubisz et al., 2009) identifica a presença de estrutura na população, bem como a proporção do genoma de cada acesso que advém de outros grupos, e foi utilizado para determinar se existia uma ou mais populações na área de coleta, via simulação do melhor número de agrupamentos detectados. Os parâmetros utilizados foram: com 500 mil iterações Cadeia de Markov Monte Carlo Markov (MCMC), após "burn-in" de 100 mil iterações, com o modelo admixture do programa Structure, com 10 simulações para cada K. A análise encontrou dois grupos sem relação com as populações geográficas (áreas de coleta), de forma que tanto as populações geográficas quanto os grupos genéticos foram examinados nas análises posteriores.

As estimativas de diversidade genética incluíram o número de alelos (A), a heterozigosidade observada (Ho) e esperada (He), e o coeficiente de endogamia (f), calculados para cada loco por meio do programa Arlequin v.3.01 (Excoffier et al., 2006). Para examinar a estrutura genética das populações geográficas e os grupos genéticos, foi efetuada a análise de variância molecular (Amova) (Michalakis \& Excoffier, 1996) e estimado o grau de diferenciação (FST) entre as populações, com o programa GenAlEx (Peakall \& Smouse, 2006). 


\section{Resultados e Discussão}

Copaifera reticulata produz um óleo de aspecto líquido, fino, odor fraco e de coloração amarelo-dourada (73,3\% das plantas), mas com variações (amarelomédia, 16,7\%; amarelo-clara, 10\%). Alencar (1982) sugere que, além do tipo de copaíba, as características do local de crescimento das árvores também afetam a coloração do óleo-resina.
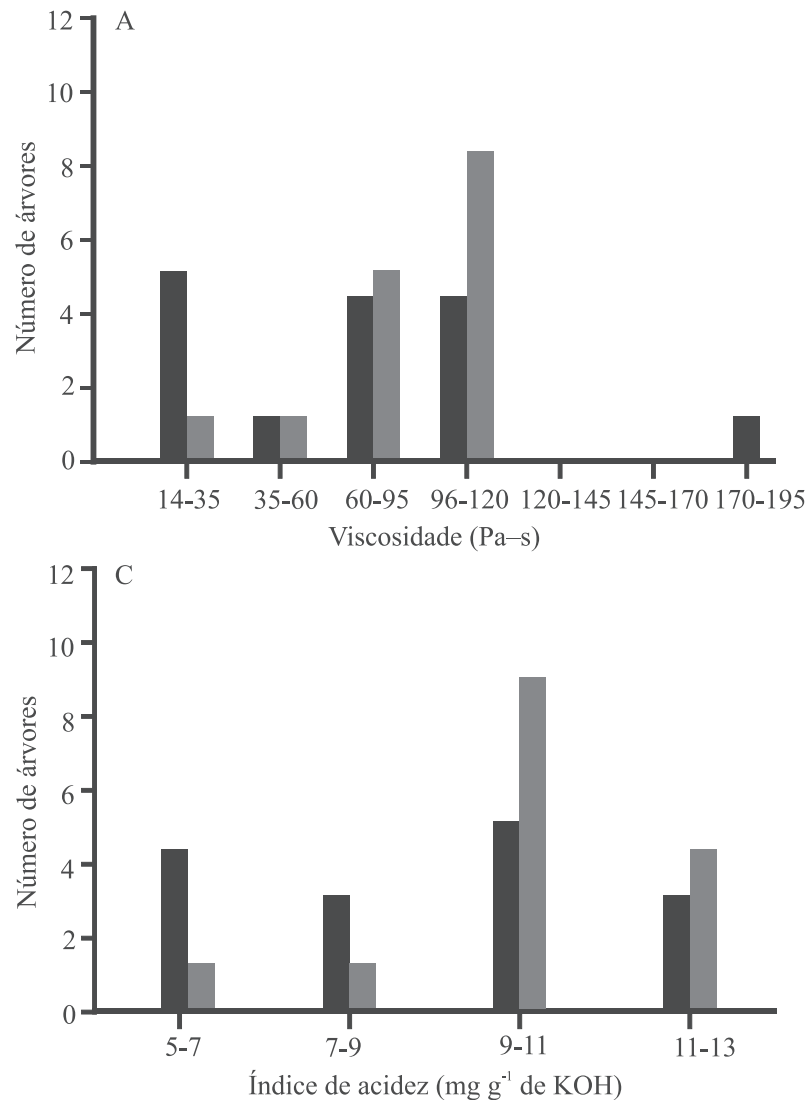

A viscosidade variou intensamente entre as áreas de coleta, enquanto a densidade nem tanto (Figura $1 \mathrm{e}$ Tabela 1). Segundo Rigamonte-Azevedo et al. (2006), C. reticulata apresenta, no Acre, maior frequência de árvores com óleo-resina de alta viscosidade, o que está de acordo com os resultados de Plowden (2003). Acredita-se que as variações físicas do óleo-resina são decorrentes de atributos genéticos e ambientais (Alencar, 1982; Cascon, 2004).
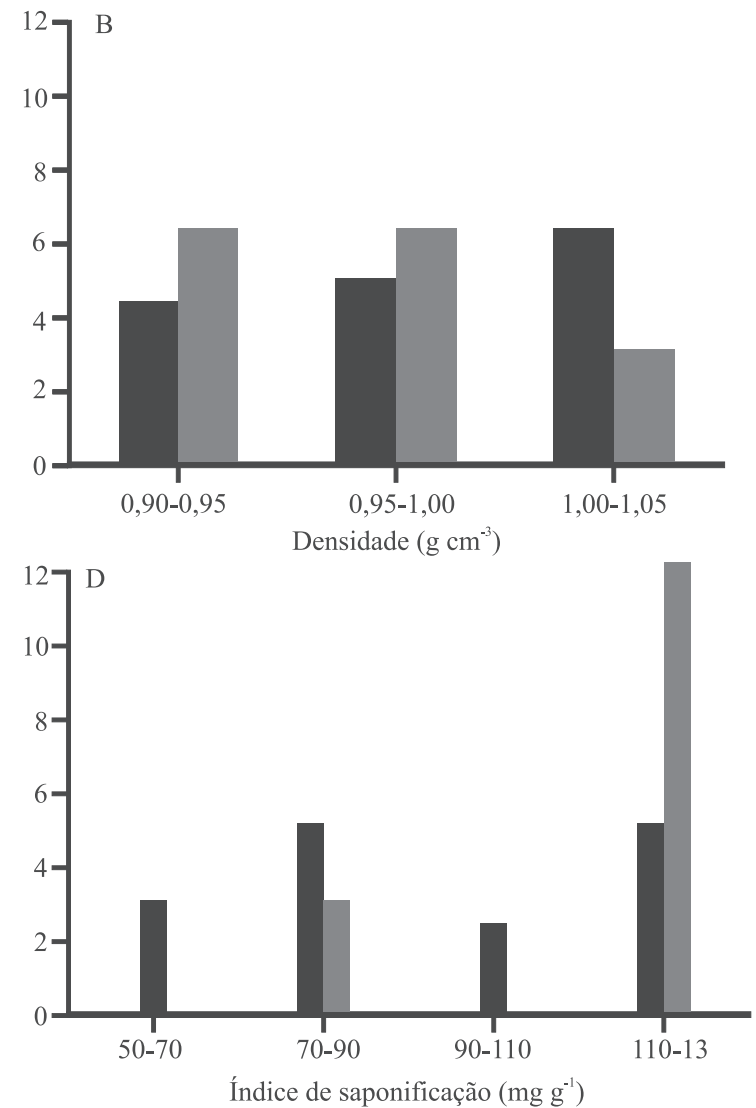

Plantas Km 67 Plantas Km 72

Figura 1. Variação: viscosidade (A), densidade (B), índice de acidez (C) e índice de saponificação (D) do óleo resina de Copaifera reticulata, nas áreas de coleta do $\mathrm{Km} 67$ e Km 72, na Floresta Nacional do Tapajós, Pará.

Tabela 1. Média \pm desvio-padrão de características físico químicas de óleo-resina obtido de Copaifera reticulata, em duas áreas de coleta na Floresta Nacional do Tapajós.

\begin{tabular}{|c|c|c|c|c|c|}
\hline \multirow[t]{2}{*}{ Característica } & \multicolumn{2}{|c|}{ Área do Km 67} & \multicolumn{2}{|c|}{ Área do Km 72} & \multirow[t]{2}{*}{ Média } \\
\hline & Média \pm dp & Amplitude $^{(1)}$ & Média $\pm d p$ & Amplitude $^{(1)}$ & \\
\hline Densidade $\left(\mathrm{g} \mathrm{cm}^{-3}\right)$ & $0,97 \pm 0,05$ & $0,94-1,01$ & $0,98 \pm 0,05$ & $0,95-1,03$ & 0,98 \\
\hline Viscosidade $(\mathrm{Pa}-\mathrm{s})$ & $79,04 \pm 32,29$ & $18,54-114,49$ & $85,51 \pm 49,30$ & $18,80-187,66$ & 82,27 \\
\hline Índice de refração & $1,51 \pm 0,01$ & $1,51-1,51$ & $1,51 \pm 0,00$ & $1,51-1,51$ & 1,51 \\
\hline Índice de acidez $\left(\mathrm{mg} \mathrm{g}^{-1}\right)$ & $10,17 \pm 1,62$ & $6,68-11,19$ & $9,62 \pm 1,89$ & $6,20-11,44$ & 9,89 \\
\hline Índice de saponificação (mg g $\mathrm{g}^{-1}$ de $\left.\mathrm{KOH}\right)$ & $109,84 \pm 14,76$ & $80,85-124,12$ & $100,63 \pm 20,86$ & $58,92-127,91$ & 105,23 \\
\hline Índice de éster & $98,99 \pm 13,38$ & $66,07-116,35$ & $89,05 \pm 20,52$ & $48,81-116,71$ & 94,02 \\
\hline
\end{tabular}

${ }^{(1)}$ Valores mínimo e máximo de 15 plantas por área. 
A acidez foi baixa e o índice de saponificação alto, nas amostras das duas áreas de coleta (Figura 1). Souza (2010) relatou baixo índice de acidez para C. multijuga Hayne (9,4 mg g $^{-1}$ de $\left.\mathrm{KOH}\right)$ em Rondônia, com baixo índice de saponificação $\left(15,4 \mathrm{mg} \mathrm{g}^{-1}\right.$ de $\left.\mathrm{KOH}\right)$; em contraste com os observados para $C$. piresii Ducke, que apresentou acidez de $48,9 \mathrm{mg} \mathrm{g}^{-1}$ e saponificação de $64,9 \mathrm{mg} \mathrm{g}^{-1}$, índices considerados altos.

A variação observada nos óleos-resina propicia diferentes utilizações industriais. Um óleo-resina mais fino e menos ácido tem maior fração de óleos essenciais e pode ser destinado a indústrias farmacêuticas, ou utilizado como fixador de perfumes em empresas de cosméticos. Os mais espessos, densos e ácidos podem ser empregados em indústrias de cosméticos, para a fabricação de sabonetes, xampus e condicionadores (Barbosa et al., 2009). No entanto, a alta variabilidade observada indica que cada árvore deve ser analisada separadamente, e que grupos de árvores com características similares também devem ser manejados separadamente. Esse manejo pode agregar valor ao produto, pois a mistura de óleos-resina diminui sua qualidade. No entanto, o manejo e exploração das árvores de forma separada aumentam os custos do plano de manejo, o que poderia erodir o valor adicional captado pela comercialização de óleos-resinas mais uniformes.

Os seis locos desenvolvidos para C. langsdorffii revelaram um bom número de alelos em $C$. reticulata, com média de 13 alelos por loco. Essa média é inferior em apenas 53\% à obtida por Ciampi et al. (2000) em C. langsdorffii. Esses autores relataram taxa de transferibilidade de $75 \%$ de $C$. langsdorffi para C. reticulata. Uma alta transferibilidade de locos SSR ocorre entre espécies taxonomicamente relacionadas, mas a transferibilidade absoluta (100\% dos locos) ocorre apenas em consequência da homologia da sequência de DNA das regiões que flanqueiam os microssatélites (Collevatti et al., 1999), o que que não ocorreu com os locos CL20 e CL39 em C. reticulata.

As simulações com o programa Structure determinaram que a probabilidade de existirem dois grupos é duas vezes maior do que a de três, e seis vezes maior do que a de quatro, pelo cálculo de $\Delta \mathrm{K}$ proposto por Evanno et al. (2005). As simulações para $\Delta \mathrm{K}=2$ não apresentaram relação com as duas áreas de coleta (Figura 2). A probabilidade de existirem duas populações entre as áreas era, de fato, pequena, em razão da pequena distância geográfica (aproximadamente $5 \mathrm{~km}$ ), mas a existência de dois grupos genéticos era esperada, e indica que a Flona Tapajós pode representar uma zona de contato entre populações isoladas pela fragmentação da floresta, antes da conquista europeia. Esta explicação se baseia na presença da cacicada Tapajós, que ocupou a região do Baixo Rio Tapajós e áreas adjacentes, e deixou numerosos sítios de Terra-preta de Índio (Gomes, 2011), que normalmente são cercados por áreas usadas para agricultura e manejo florestal. Em razão dessa variabilidade, tanto as áreas de coleta como os grupos genéticos foram examinados.

Duas análises de variância molecular (Amova), com respectivas estimativas de FST, examinaram duas possíveis estruturas: área geográfica de coleta no $\mathrm{Km} 67$ e $\mathrm{Km} \mathrm{72,} \mathrm{e} \mathrm{agrupamentos} \mathrm{genéticos} \mathrm{de}$ Structure (Tabela 2). A maior parte da variação genética foi encontrada dentro das áreas de coleta (97\%), com uma fraca diferenciação genética entre

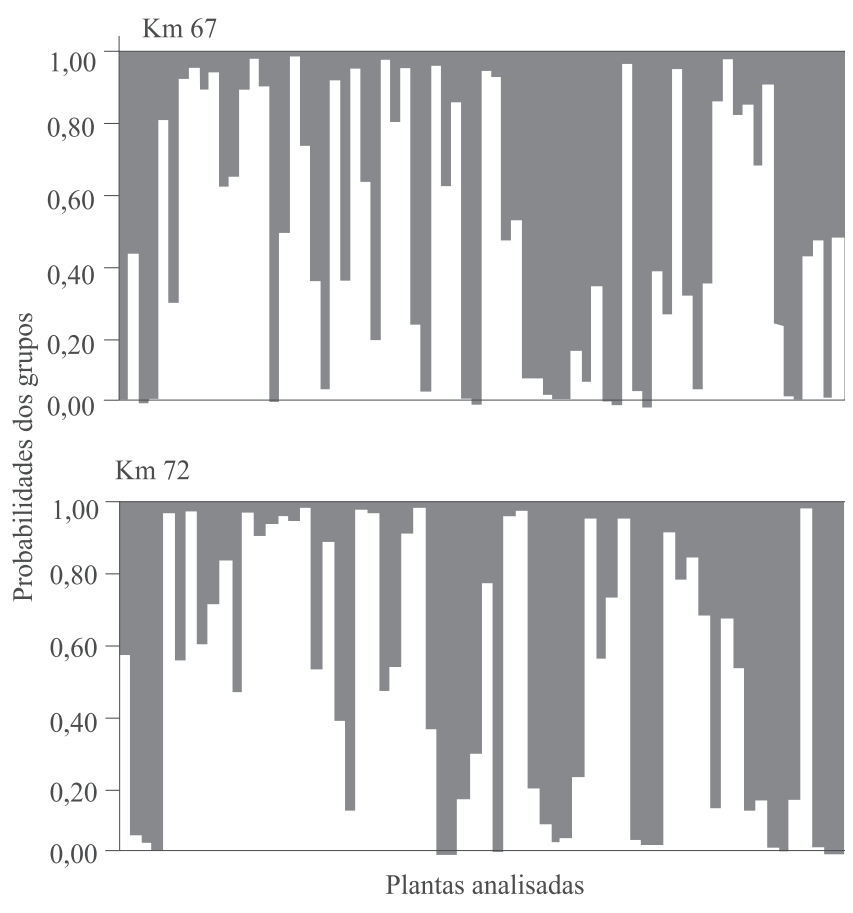

Figura 2. Probabilidade de designação das 136 plantas em dois grupos identificados pelo programa Structure $(\Delta \mathrm{K}=2)$. As cores representam os grupos como similaridades alélicas, e cada planta (linha vertical) foi avaliada quanto à probabilidade de compor um determinado grupo. As áreas geográficas do Km 67 e Km 72 encontram-se na BR 163, no limite da Floresta Nacional do Tapajós, Pará. 
as áreas $(\mathrm{FST}=0,030)$. Variação genética menor foi encontrada dentro dos grupos genéticos (93\%), com aumento correspondente na divergência $(\mathrm{FST}=0,070)$.

Tabela 2. Estrutura de variabilidade genética de Copaifera reticulata na Flona do Tapajós, Pará, pela análise de variância molecular com base em seis locos microssatélites, tendose considerado duas possíveis estruturas: áreas de coleta e grupos genéticos.

\begin{tabular}{lcccc}
\hline Fonte de variação & GL & \multicolumn{4}{c}{ Variância } & Variação (\%) & FST \\
\hline Entre áreas & 1 & 0,211 & 3 & 0,030 \\
Dentro de áreas & 134 & 6,784 & 97 & \\
\hline Total & 135 & 6,995 & 100 \\
\hline \multicolumn{5}{c}{ Grupos genéticos } \\
Entre grupos & 1 & 0,498 & 7 & 0,070 \\
Dentro de grupos & 134 & 6,640 & 93 & \\
\hline Total & 135 & 7,138 & 100 \\
\hline
\end{tabular}

Ambos os valores de FST foram baixos, o que indica fraca estruturação. Pinto et al. (2004) encontraram divergência alta $(17,5 \%)$ entre populações de C. langsdorffii em Lavras, MG, por meio de isoenzimas. Ao usar tanto AFLP como microssatélites, Ciampi et al. (2000) observaram que $90 \%$ variabilidade genética em C. langsdorffii ocorre dentro das populações, e 10\% entre populações.

Nos 136 indivíduos adultos, avaliados com seis locos microssatélites, foram identificados 78 alelos (Tabela 3). Martins et al. (2008) encontrou 108 alelos em seis locos, para C. langsdorffii, em fragmentos florestais do Portal de Paranapanema, SP. Desses 108 alelos, 18 eram privados. Ciampi et al. (2000) encontraram 196 alelos, em oito locos, e detectaram alelos privados em apenas poucos indivíduos. Em contraste, no presente estudo, foram encontrados 34 alelos privados, o que

Tabela 3. Diversidade genética avaliada com base em seis locos microssatélites, para 136 amostras de Copaifera reticulata na Flona do Tapajós, Pará, tendo-se considerado os agrupamentos de indivíduos de acordo com as áreas de coleta (km 67 e 72) e os grupos genéticos.

\begin{tabular}{|c|c|c|c|c|c|c|c|c|}
\hline \multirow[t]{2}{*}{ Parâmetro } & \multirow[t]{2}{*}{ Característica } & \multicolumn{6}{|c|}{ Locos } & \multirow[t]{2}{*}{ Todos } \\
\hline & & CL01 & CL02 & CL06 & CL27 & CL32 & CL34 & \\
\hline & \multicolumn{8}{|c|}{ Áreas de coleta } \\
\hline \multirow{5}{*}{$\mathrm{Km} 67(\mathrm{~N}=72)$} & A & 6 & 14 & 7 & 10 & 14 & 11 & 62 \\
\hline & $\mathrm{P}$ & 2 & 6 & & 3 & 2 & 1 & 14 \\
\hline & Ho & 0,444 & 0,394 & 0,357 & 0,653 & 0,471 & 0,535 & 0,476 \\
\hline & $\mathrm{He}$ & 0,628 & 0,821 & 0,669 & 0,83 & 0,835 & 0,785 & 0,761 \\
\hline & $\mathrm{f}$ & 0,293 & 0,52 & 0,466 & 0,214 & 0,437 & 0,318 & 0,375 \\
\hline \multirow{5}{*}{$\mathrm{Km} 72(\mathrm{~N}=64)$} & A & 10 & 11 & 8 & 14 & 13 & 11 & 67 \\
\hline & $\mathrm{P}$ & 3 & 3 & 1 & 3 & 4 & 2 & 18 \\
\hline & Ho & 0,578 & 0,381 & 0,217 & 0,459 & 0,569 & 0,508 & 0,452 \\
\hline & $\mathrm{He}$ & 0,701 & 0,846 & 0,665 & 0,852 & 0,825 & 0,772 & 0,777 \\
\hline & $\mathrm{f}$ & 0,176 & 0,55 & 0,674 & 0,461 & 0,31 & 0,341 & 0,419 \\
\hline & \multicolumn{8}{|c|}{ Grupos genéticos } \\
\hline \multirow{5}{*}{$N=72$} & A & 5 & 12 & 8 & 12 & 12 & 10 & 59 \\
\hline & $\mathrm{P}$ & 1 & 5 & 1 & 3 & 6 & 4 & 20 \\
\hline & Ho & 0,514 & 0,371 & 0,319 & 0,638 & 0,522 & 0,563 & 0,488 \\
\hline & $\mathrm{He}$ & 0,596 & 0,778 & 0,757 & 0,826 & 0,841 & 0,716 & 0,752 \\
\hline & $\mathrm{f}$ & 0,137 & 0,522 & 0,579 & 0,288 & 0,379 & 0,213 & 0,343 \\
\hline \multirow{5}{*}{$N=64$} & A & 8 & 14 & 7 & 14 & 9 & 8 & 60 \\
\hline & $\mathrm{P}$ & 4 & 3 & & 5 & 3 & 2 & 17 \\
\hline & Но & 0,5 & 0,407 & 0,262 & 0,484 & 0,508 & 0,475 & 0,44 \\
\hline & $\mathrm{He}$ & 0,706 & 0,851 & 0,645 & 0,825 & 0,79 & 0,75 & 0,761 \\
\hline & $\mathrm{f}$ & 0,291 & 0,522 & 0,594 & 0,413 & 0,356 & 0,366 & 0,424 \\
\hline \multirow{5}{*}{$N=136$} & \multicolumn{8}{|c|}{ Conjunto } \\
\hline & A & 9 & 17 & 8 & 12 & 17 & 15 & 78 \\
\hline & Но & 0,507 & 0,388 & 0,292 & 0,523 & 0,564 & 0,516 & 0,465 \\
\hline & $\mathrm{He}$ & 0,668 & 0,845 & 0,719 & 0,785 & 0,843 & 0,834 & 0,782 \\
\hline & $\mathrm{f}$ & 0,24 & 0,541 & 0,593 & 0,334 & 0,331 & 0,381 & 0,403 \\
\hline
\end{tabular}

A, número de alelos; P, número de alelos privados; Ho, heterozigosidade observada; He, heterozigosidade esperada; f, coeficiente de endogamia de Weir \& Cockerham (1984). 
certamente contribuiu para formação dos grupos genéticos identificados com Structure.

Os indivíduos apresentaram, em todos os locos, deficit de heterozigosidade observada em relação às proporções estimadas para $\mathrm{o}$ equilíbrio de Hardy-Weinberg, o que resultou em estimativa moderada de endogamia (Tabela 3). O equilíbrio de Hardy-Weinberg deixa de existir na presença de cruzamentos preferenciais, que pode resultar de estruturação dentro da população. A existência de grupos genéticos identificados pelo Structure indica que há estruturação na população de $C$. reticulata na Flona do Tapajós. Estimativas moderadas a altas do coeficiente de endogamia provavelmente são decorrentes de agrupamento de árvores na floresta, o que permite cruzamentos entre parentes e é relativamente comum em árvores de florestas tropicais (Dick et al., 2008). Resultado similar foi citado por Martins et al. (2008), sobre C. langsdorffii $(\mathrm{f}=0,292)$, também com o uso de seis locos.

As heterozigosidades esperadas nas áreas de coleta $(0,76)$, nos grupos genéticos $(0,75)$ e no total $(0,78)$ foram altas e similares às esperadas para outras espécies arbóreas neotropicais (Lemes et al., 2007).

\section{Conclusões}

1. Copaifera reticulata apresenta alta variabilidade genética na Floresta Nacional do Tapajós, com ampla variação nas características químicas do óleo-resina.

2. A alta variabilidade nas características químicas do óleo-resina indica ser necessário um plano de manejo que separe a extração em indivíduos e características de interesse uniformes, para que se possa obter um produto com maior valor agregado.

3. A alta variabilidade genética, mesmo com nível de moderado a alto de endogamia, indica que não há, em médio prazo, ameaças à conservação genética de C. reticulata na Floresta Nacional do Tapajós.

\section{Agradecimentos}

Ao Conselho Nacional de Desenvolvimento Científico e Tecnológico, à Coordenação de Aperfeiçoamento de Pessoal de Nível Superior e à Fundação de Amparo à Pesquisa do Estado do Amazonas, pelo apoio financeiro e concessão de bolsas; ao Instituto Brasileiro do Meio Ambiente e dos Recursos Naturais Renováveis e ao Instituto Chico
Mendes de Conservação da Biodiversidade, Santarém, PA, pelas autorizações e apoio; aos moradores das comunidades de Pedreira e São Domingos, pelo apoio e paciência durante a pesquisa de campo; à Dra. Izeni Pires Farias, da Universidade Federal do Amazonas, pelo apoio com o sequenciador.

\section{Referências}

ALENCAR, J. da C. Estudos silviculturais de uma população natural de Copaifera multijuga Hayne - Leguminosae, na Amazônia central. 2 - Produção de óleo-resina. Acta Amazonica, v.12, p.75-89, 1982.

BARBOSA, K. de S.; YOSHIDA, M.; SCUDELLER, V.V. Detection of adulterated copaiba (Copaifera multijuga Hayne) oil-resins by refractive index and thin layer chromatography. Revista Brasileira de Farmacognosia, v.19, p.57-60, 2009.

BARRETO JUNIOR, A.G.; BISCAIA JUNIOR, E.C.; VEIGA JUNIOR, V.F. da.; PINTO,A.C.; CARVALHAES, S.F. de; MACIEL, M.A.M. Cromatografia de troca iônica aplicada ao isolamento da fração ácida do óleo de copaíba (Copaifera multijuga) e da sacaca (Croton cajucara). Química Nova, v.28, p.719-722, 2005.

CASCON, V. Copaíba - Copaifera spp. In: CARVALHO, J.C.T. (Ed.). Fitoterápicos antiinflamatórios: aspectos químicos, farmacológicos e aplicações terapêuticas. Ribeirão Preto: Tecmedd, 2004. 480p.

CIAMPI, A.Y.; BRONDANI, R.P.V.; GRATTAPAGLIA, D. Otimização de sistemas fluorescentes de genotipagem multiloco e desenvolvimento de marcadores microssatélites para Copaifera langsdorffii Desf. (copaíba) Leguminosae - Caesalpinoideae. Brasília: Embrapa Recursos Genéticos e Biotecnologia, 2000. 40p. (Embrapa Recursos Genéticos e Biotecnologia. Boletim de pesquisa, 16).

COLLEVATTI, R.G.; BRONDANI, R.V.; GRATTAPAGLIA, D. Development and characterization of microssatellite markers for genetic analysis of a Brazilian endangered tree species Caryocar brasiliense. Heredity, v.83, p.748-756, 1999.

DICK, C.W.; HARDY, O.J.; JONES, F.A.; PETIT, R.J. Spatial scales of pollen and seed-mediated gene flow in tropical rain forest trees. Tropical Plant Biology, v.1, p.20-33, 2008.

DOYLE, J.J.; DOYLE, J.S. Isolation of plant DNA from fresh tissue. Focus, v.12, p.13-15, 1987.

EVANNO, G.; REGNAUT, S.; GOUDET, J. Detecting the number of clusters of individuals using the software Structure: a simulation study. Molecular Ecology, v.14, p.2611-2620, 2005.

EXCOFFIER, L.G.L.; SCHNEIDER, S. Arlequin (version 3.0): an integrated software package for population genetics data analysis. Evolutionary Bioinformatics, v.1, p.47-50, 2006.

GLAUBITZ, J.C. CONVERT: a user-friendly program to reformat diploid genotypic data for commonly used population genetic software packages. Molecular Ecology Notes, v.4, p.309-310, 2004. 
GOMES, D.M.C. Cronologia e conexões culturais na Amazônia: as sociedades formativas da região de Santarém - PA. Revista de Antropologia, v.54, p.269-314, 2011.

HOMMA, A.K.O. Extrativismo vegetal na Amazônia: limites e oportunidades. Belém: Embrapa-CPATU; Brasília: Embrapa-SPI, 1993. 202p.

HORWITZ, W. (Ed.). Official Methods of Analysis of AOAC International. $18^{\text {th }}$ ed. Gaithersburg: AOAC International, 2005. $1141 \mathrm{p}$.

HUBISZ, M.J.; FALUSH, D.; STEPHENS, M.; PRITCHARD, J.K. Inferring weak population structure with the assistance of sample group information. Molecular Ecology Resources, v.9, p.1322-1332, 2009.

KALIA, R.K.; RAI, M.K.; KALIA, S.; SINGH, R.; DHAWAN, A.K. Microsatellite markers: an overview of the recent progress in plants. Euphytica, v.177, p.309-334, 2011.

LEMES, M.R.; GRATTAPAGLIA, D.; GROGAN, J.; PROCTOR, J.; GRIBEL, R. Flexible mating system in a logged population of Swietenia macrophylla King (Meliaceae): implications for the management of threatened neotropical tree species. Plant Ecology, v.192, p.169-179, 2007.

MARTINS, K.; SANTOS, J.D. dos; GAIOTTO, F.A.; MORENO, M.A.; KAGEYAMA, P.Y. Estrutura genética populacional de Copaifera langsdorffi Desf. (Leguminosae - Caesalpinioideae) em fragmentos florestais no Pontal do Paranapanema, SP, Brasil. Revista Brasileira de Botânica, v.31, p.61-69, 2008.

MARTINS-DA-SILVA, R.C.V.; PEREIRA, J.F.; LIMA, H.C. de. O genêro Copaifera (Leguminosae-Caesalpinioideae) na Amazônia brasileira. Rodriguésia, v.59, p.455-476, 2008.

MÉTODOS físico-químicos para análise de alimentos. São Paulo: Instituto Adolfo Lutz, 2005. 600p.
MICHALAKIS, Y.; EXCOFFIER, L. A generic estimation of population subdivision using distances between alleles with special reference for microsatellite loci. Genetics, v.142, p.1061-1064, 1996.

PEAKALL, R.; SMOUSE, P. Genalex 6: genetic analysis in Excel. Population genetic software for teaching and research. Molecular Ecology Notes, v.6, p.288-295, 2006.

PINTO, S.I. do C.; SOUZA, A.M. de; CARVALHO, D. de. Variabilidade genética por isoenzimas em populações de Copaifera langsdorfii Desf. em dois fragmentos de mata ciliar. Scientia Forestalis, v.65, p.40-48, 2004.

PLOWDEN, C. Production ecology of copaíba (Copaifera spp.) oleoresin in the eastern Brazilian Amazon. Economic Botany, v.57, p.491-500, 2003.

RIGAMONTE-AZEVEDO, O.C.; WADT, P.G.S.; WADT, L.H. de O. Potencial de produção de óleo-resina de copaíba (Copaifera spp) de populações naturais do sudoeste da Amazônia. Revista Árvore, v.30, p.583-591, 2006.

SOUZA, F.D.R. O manejo do óleo-resina de Copaifera spp. realizado pelas etnias Arara (Karo rap) e Gavião (Ikolen) na Terra Indígena Igarapé Lourdes, Rondônia. 2010. 67p. Dissertação (Mestrado) - Instituto Nacional de Pesquisas da Amazônia, Manaus.

VASCONCELOS, A.F.F. de; GODINHO, O.E.S. Uso de métodos analíticos convencionados no estudo da autenticidade do óleo de copaíba. Química Nova, v.25, p.1057-1060, 2002.

VEIGA JUNIOR, V.F.; PINTO, A.C. O gênero Copaifera L. Química Nova, v.25, p.273-286, 2002.

WEIR, B.S.; COCKERHAM, C.C. Estimating f-statistics for the analysis of population-structure. Evolution, v.38, p.1358-1370, 1984.

Recebido em 18 de maio de 2012 e aprovado em 24 de outubro de 2012 